\title{
LEITURA E FORMAÇÃO DO LEITOR
}

Assumir um conceito amplo e político a respeito da leitura é considerá-la uma prática cidadã e não simplesmente uma ação reduzida a tarefas desprovidas de significados. É compreendê-la em contextos de comunicação relevantes e plurais, que preveem um diálogo ativo com o texto, concebido como lugar de interação, assim como é entender o seu leitor um edificador de sentidos. Desse modo, este dossiê "Leitura e formação do leitor" reúne trabalhos resultantes de estudos bibliográficos que se voltem para teorias e concepções de leitura, bem como provenientes de pesquisas aplicadas que visem à formação do leitor. Encontramos, ao longo do volume, um conjunto de textos que se voltam para a investigação de práticas e discussão de abordagens específicas para a formação do leitor e também artigos que buscam a análise detida de testes de leitura e de estruturas de previsão do leitor dentro do texto.

Poliana Bernabé Leonardeli, Aline Morais Silva, Bárbara Miguel Ferrari, em "A literatura infantojuvenil nos espaços escolares e a formação do leitor na educação básica", defendem que o professor tem papel fundamental como mediador ao estimular os estudantes para conhecer o literário, por meio de livros, projetos e de ações em espaços de leitura. Partindo do efetivo encontro entre leitor e leitura literária em uma escola no interior paulista, Thiago Alves Valente apresenta o processo de implementação de um clube do livro em "Clube de leitura: estratégia para formação de leitores". Nesse sentido, baseia-se em pressupostos teóricos que sistematizam a prática pedagógica e que colocam a leitura do texto literário na escola em lugar privilegiado. Trabalho semelhante é o de Alessandra Maria de Mesquita, "Levar a ler em "lugares distantes": uma proposta de leitura". Nele, Mesquita organiza uma biblioteca escolar e desenvolve atividades de leitura no município de Monte Alegre (PA), assim, investiga condições e possibilidades para instituir um espaço de leitura. Ivana Esteves Passos de Oliveira apresenta "Estratégias de leitura e literatura infantil capixaba: formando leitores na EMEF Custódia Dias de Campos" que também tem como palco o espaço da biblioteca escolar, local onde passaram a ocorrer práticas de leitura literária de estudantes, cujo foco se volta para alunos do quarto ano das séries iniciais, por meio de pesquisa de observação participante e de pesquisa-ação. "A subjetividade na formação do leitor literário no espaço do Programa BALE” (Biblioteca Ambulante e Literatura nas Escolas) é o artigo de Keutre Gláudia da Conceição Soares Bezerra e Maria Lúcia Pessoa Sampaio que expressa os sentidos subjetivos mobilizados no ato de ler dos participantes. Desse modo, defendem que a participação dos sujeitos no Programa levaos a transformar suas atitudes com relação à leitura e a ampliar sua atuação como leitores.

Moisés Selfa Sastre e Enric Falguera Garcia apresentam "La promoción de la lectura en la escuela: el caso del Pla d'Impuls a la Lectura en Cataluña" para expor uma medida implantada desde 2011 em escolas catalãs para fomentar o hábito de ler e o desenvolvimento da competência leitora. Para tanto, definem os objetivos do Plano e sua relação com os conceitos de saber ler, ler nas áreas do currículo e o gosto pela leitura. Um programa de leitura também é retratado por Ana Carolina Palma Francisco Avila e Cláudio Marcondes de Castro Filho. Em "Limites e possibilidades da contribuição do Programa Sala de Leitura na formação de leitores no contexto escolar", os pesquisadores fazem um estudo de caso para discutir possibilidades e limitações do 
Programa Sala de Leitura para a formação de leitores de uma escola da cidade de Ribeirão Preto (SP) e fazem sugestões sustentadas em momentos de leitura livre e no ensino de estratégias de leitura.

Com o intuito de propor atividades para desenvolvimento da compreensão leitora e da consciência textual para estudantes do final do Ensino Fundamental, Patricia de Andrade Neves, Caroline Bernardes Borges e Vera Wannmacher Pereira exploram a crônica e auxiliam docentes de Língua Portuguesa no trabalho cotidiano com leitura em artigo intitulado "A compreensão e a consciência textual no gênero crônica: uma proposta de ensino para alunos do $9^{\circ}$ ano do ensino fundamental".

Marta Aparecida Broietti Henrique, com base em conceitos relacionados aos estudos do discurso, faz análise de uma materialidade linguística para mostrar como conhecer concepções teóricas pode favorecer o desenvolvimento de um trabalho de leitura na escola. Dessa maneira, "Leitura e formação do leitor: a construção de efeitos de sentidos no processo de interação verbal" constata que interações verbais são responsáveis por ajudar o leitor a reconhecer os sentidos do texto.

Com a finalidade de explorar provas do ENADE (Exame Nacional de Desempenho dos Estudantes), Fernando Teixeira Luiz analisa três questões do Caderno de Formação Geral propostas para os cursos de Pedagogia (2011), Administração (2015) e Ciências Biológicas (2017) no artigo "Quem tem medo do ENADE? Um estudo acerca das habilidades de leitura configuradas na proposta de avaliação das provas de "Formação Geral"". Nesse sentido, verifica como habilidades de leitura são fundamentais para a resolução das questões. Na sequencia temos o artigo de Fabíola Ribeiro Faria, Luiz Percival Leme Britto e Zair Henrique Santos: "As diretrizes da Base Nacional Comum Curricular do Ensino Médio para o ensino de literatura: uma análise". Os autores apresentam as diretrizes contidas na BNCC e refletem sobre as contribuições da leitura literária na formação de adolescentes e jovens à luz da concepção de trabalho educativo postulada pela Pedagogia Histórico-crítica, apresentando as recomendações e analisando documentalmente cada uma das habilidades descritas para a área.

"O "re-enactment", a "apropriação" e o "cover" como modelos de produção e ensino de literatura - uma possibilidade da abordagem triangular" é o texto de Eduardo de Almeida Santos que explicita um estudo de caso e os resultados obtidos em projetos como "Apalpe" (A Palavra da Periferia) e "Agências de Redes para juventude" do Rio de Janeiro. Métodos de criação, processos de escrita e criatividade fazem-se presentes neste trabalho com o público jovem.

Beatriz dos Santos Feres e Júlia Vieira Correia destacam um autor específico, Ziraldo, para analisar o processo de referenciação em dez livros ilustrados do autor, em artigo denominado "Da referenciação à mediação de leitura: um estudo de obras de Ziraldo". Conforme as estudiosas, a pesquisa parte da hipótese de que o signo verbal não se destaca nos livros ilustrados e revela que a referenciação é dupla nessa categoria de livro. Assim, a leitura e a formação do leitor são temas que geram debates em diferentes perspectivas e que ainda têm muito a dizer a nós, professores e pesquisadores. $\mathrm{O}$ acesso a este dossiê pode, pois, nos ajudar a conhecer um pouco mais desse motivador campo de investigação.

A sessão de artigos de temática livre é composta por um conjunto de textos que dialoga bastante com o tema do número e apresenta discussões em que a leitura perpassa outros objetos de investigação. Assim temos, abrindo essa sessão, o texto de Luis Silva e Juliana Souza Lopes Hott da Rocha, "Livro didático de língua portuguesa: 
um gênero de discurso multimodal" que traz reflexões sobre a interface entre livro didático, gênero de discurso e multimodalidade. Os autores buscaram a caracterização do livro didático como um gênero de discurso multimodal, uma vez que apresenta uma simbiose de linguagens, a presença de elementos de discurso multimodal abre perspectiva para que o aluno se torne um leitor crítico, se o livro didático for trabalhado no processo de ensino-aprendizagem como um gênero multimodal.

Graziella Steigleder Gomes autora de "Estratégias de leitura em manuais de autoestudo preparatórios para o TOEFL iBT" investiga as estratégias de leitura descritas em manuais de autoestudo dirigidos a candidatos ao TOEFL, entre as mais frequentes e relevantes, estão skimmimg e scanning, sendo a leitura voltada à fruição desencorajada. Percebe-se que, mesmo que os candidatos possuam internalizadas muitas habilidades leitoras, é a tomada de consciência sobre como utilizá-las (tornando-as, dessa forma, em estratégias) que, entre outros fatores, determinará seu sucesso ou não na seção de reading do teste supracitado.

Taciane Ienk e Rosana Apolonia Harmuch em "Viagens na minha terra e Peter Pan: a autoteorização literária e suas relações com o ensino" discutem de que forma a autoteorização literária contribui com o ensino de literatura no Ensino Médio e abordam a teoria a partir das próprias obras literárias. Para explorá-lo foram selecionadas as obras Viagens na minha terra, de Almeida Garrett, e Peter Pan, de James Barrie. Por fim, Lucicláudia Alves Silva e Naelza Araújo Wanderley no artigo "A representação da natureza em poemas de Patativa do Assaré" apresentam as formas de representação da natureza a partir da leitura dos poemas "O Sabiá e o Gavião" e "A menina e a cajazeira", de Patativa do Assaré, autor de uma poesia marcada de profundo sentimentalismo, através da qual, na maioria das vezes, os elementos da natureza funcionam com uma espécie de suporte para a construção e a expressão desse lirismo.

Encerrando o número temos a resenha "Reenunciando democracia em vertigem: sob as lentes de Bakhtin e o círculo" de autoria de Eliete Correia Santos e Wilder Kleber Fernandes de Santana sobre o documentário Democracia em vertigem, de 2019. Os autores articulam o ensino estético-artístico à concepção dialógica do discurso, inserindo a discussão sobre o modelo metodológico-analítico como exemplo, para despertar o senso crítico de sujeitos leitores e expectadores.

Berta Lúcia Tagliari Feba Renata Junqueira de Souza 